\title{
USE OF GESTURE FOR CORRECTING PRONUNCIATION ERRORS
}

\author{
Amelyn A Thompson \\ (amelynthompson@gmail.com) \\ Willy A Renandya \\ (willy.renandya@nie.edu.sg) \\ National Institute of Education, Nanyang Technological University \\ 1 Nanyang Walk, Singapore 637616
}

\begin{abstract}
The role of gesture in second language acquisition (SLA) has recently become a promising area of research, characterized by the growing number of empirical research studies that examine the potential of incorporating gestures in such areas as the teaching of grammar, vocabulary, and pronunciation. This paper focuses on how gesture can be productively used to help students notice and subsequently correct their pronunciation errors, both segmental and suprasegmental errors. First, a critical review of the literature is presented in which we carefully explore recent research on oral corrective feedback and the role that gesture plays in facilitating comprehension and acquisition. Next, pedagogical implications are considered in which we discuss a pedagogical framework that language teachers can use as a guide for incorporating gestures in pronunciation instruction. Finally, future research possibilities are discussed, including suggestions for more robust research design and new areas to investigate.
\end{abstract}

Keywords: corrective feedback, gesture, pronunciation, second language acquisition

DOI: http://dx.doi.org/10.15639/teflinjournal.v31i2/342-359

This article focuses on the role of gesture in oral corrective feedback (CF) in pronunciation teaching and is situated within the broader interactional classroom context of second language acquisition (SLA). The paper is inspired by a recent state-of-the-art article on interaction within instructed SLA in which the authors mentioned that gesture is a promising area of research that has recently attracted 
the attention of mainstream SLA researchers (Loewen \& Sato, 2018). McCafferty and Gullberg (2008), for example, observed that the field of gesture research is relevant to SLA as it hones in on two vital components of SLA theories: communicative and psychological development. Crucially, gesture cooccurring with input has been noted to enhance second-language learners ' comprehension, which might gradually lead to improved acquisition (Dargue et al., 2019; McCafferty \& Gullberg, 2008). The role of gesture would thus be an interesting added dimension to explore within the well-researched field of CF.

Theoretically, this paper draws on three main concepts: the interaction hypothesis, focus on form, and the noticing hypothesis. These theoretical constructs will be highlighted in the following section. Regarding CF, research findings are not conclusive as to whether input-providing feedback such as recasts is more effective than output-prompting feedback such as prompts (Ellis, 2017). Nevertheless, and perhaps more importantly, a meta-analysis conducted by Brown (2016) found that across teachers' use of CF in the classroom, recasts stood at $57 \%$, which outweighed prompts at $30 \%$. Thus, it seems prudent to focus on recasts to determine or enhance their efficacy since they are most commonly used by teachers in the classroom.

Incorporating research on gestures, Nakatsukasa (2016) maintains that gestures could increase the long-term effects of recasts on specific linguistic structures and proposes that an intervention study focusing on pronunciation acquisition would be a viable and valuable avenue for researching the potential impact of combining gesture and recasts. This is because there has been a lack of focus on the role of gesture, with the dearth of studies on pronunciation teaching (Smotrova, 2017).

Within the area of pronunciation teaching, the outdated goal of attaining native-like fluency has been cast aside in favor of the goal of intelligibility, that is, the extent to which one's speech is easily understood among people of different first and second language backgrounds (Loewen, 2015). This is especially relevant in light of the evolution of English as a lingua franca, where L2 speakers are in the majority. It is not pedagogically tenable to aim for nativelike pronunciation; instead, teachers should focus more on helping L2 learners develop intelligible speech. More specifically, in the area of pronunciation, Wong (2016) pinpoints word stress as an area in need of further research, crucially because it often affects comprehension. If research findings indicate that gesture is useful in such an endeavor, gesture may find useful and practical applications in the second or foreign language classrooms. 
This article recognises the potential for further research regarding the use of gesture in correcting pronunciation errors, and aims to review research that would help to illuminate the way forward in such research. Given the dearth of empirical studies investigating the use of gestures in pronunciation instruction (Iizuka et al., 2020), this article considers a broad overview of research regarding gesture and oral corrective feedback, before narrowing the focus to gesture in both corrective feedback and the teaching of pronunciation. This will provide a foundation for the conceptualisation of research design investigating gestures used in correcting pronunciation errors. Furthermore, pedagogical implications are considered, with examples of activities incorporating gesture during pronunciation lessons in the classroom. These will provide concrete ideas for designing independent variables when examining the efficacy of gesture accompanying either segmental or suprasegmental features in pronunciation instruction. Finally, several noteworthy points arising from the review of the literature will be presented, in the hope of avoiding potential pitfalls in the research design, as well as drawing attention to some aspects that warrant closer attention in future research efforts.

\section{WHAT IS GESTURE?}

According to McNeill (1992), gestures are hand or arm movements that usually go together with speech; they may be categorized in four main ways: iconic, metaphoric, deictic, or beat gestures. Vitally, McNeill (2005) highlighted the "co-expressive" nature of speech and gesture, as they work together to convey different aspects of a single idea (p. 22). With reference to McNeill (1992), an explanation of these gestures as summarized by Dargue et al. (2019) is presented below. Dargue et al.'s (2019) explanation of these gestures, which was based on McNeill (1992), is summarized in Table 1 below.

Table 1. Types of Gestures

\begin{tabular}{lll}
\hline Type of Gesture & Purpose & Example \\
\hline Iconic & $\begin{array}{l}\text { representing concrete } \\
\text { things or actions }\end{array}$ & $\begin{array}{l}\text { making a fist and raising it up } \\
\text { while saying "the boy picked up the } \\
\text { bucket" }\end{array}$ \\
\hline Metaphoric & $\begin{array}{l}\text { representing abstract } \\
\text { metaphors }\end{array}$ & $\begin{array}{l}\text { moving a hand upwards while } \\
\text { saying "my grades have improved" }\end{array}$ \\
\hline
\end{tabular}


Thompson \& Renandya, Use of Gesture for Correcting Pronunciation Errors 345

\begin{tabular}{lll}
\hline Type of Gesture & Purpose & Example \\
\hline Deictic & $\begin{array}{l}\text { indicating an event, } \\
\text { direction, or object }\end{array}$ & $\begin{array}{l}\text { pointing to an apple while saying } \\
\text { "apple" }\end{array}$ \\
\hline Beat & $\begin{array}{l}\text { rhythmic with no } \\
\text { semantic relation to what } \\
\text { is being said }\end{array}$ & $\begin{array}{l}\text { flicking hands rhythmically while } \\
\text { saying "book" }\end{array}$ \\
\hline
\end{tabular}

There is conjecture as to why such gestures help students to comprehend better. One long-established theory suggests that gestures focus students' attention on what is being said, thus increasing the probability the language and contents get processed at a deeper level (Dargue et al., 2019). This is in line with Schmidt's (2012) noticing hypothesis, which will be discussed in more detail in the following section.

\section{GESTURE AND THE NOTICING HYPOTHESIS}

Schmidt's noticing hypothesis originated in the 1980s, and simply states that input cannot become intake (and thus useful for subsequent processes of acquisition) unless it is consciously noticed by learners (Schmidt, 2012). Taking this a step further, the notion of "noticing the gap" comes into play, where learners must first consciously compare their own erroneous output against target language input, in order to recognize and correct their errors (Schmidt, 2012, p. 30 ). On a related note, the interaction hypothesis states that interaction allows learners to negotiate meaning during communication breakdown, which helps them notice the difference between their mistake(s) and the target form (Loewen, 2015). This interaction often involves cases of oral CF. Focus on form (FonF) instruction aims to combine attention on meaning and form, and involves drawing attention to form in a more explicit way (Loewen, 2015). In class, this can happen during $\mathrm{CF}$ that occurs in a communicative task. For instance, students 'attention could be drawn to stressed syllables through the use of beat gestures, which would facilitate noticing and recognition of errors, gradually leading to more accurate production. 


\section{ORAL CORRECTIVE FEEDBACK}

This paper's main focus is on gesture accompanying oral $\mathrm{CF}$ that occurs during interaction in a classroom context. Loewen and Sato (2018) identify three main distinctions: feedback that provides negative or positive evidence, inputproviding or output-prompting feedback, and implicit or explicit feedback. In the first case, negative evidence shows learners what is not possible in a language, while positive evidence gives accurate and acceptable examples (Loewen \& Sato, 2018). Secondly, the teachers supply the correction in input-providing feedback, while output-prompting feedback challenges the learner to do so (Ellis, 2017). Finally, implicit feedback would lead to incidental learning, while explicit feedback leads to noticing and intentional learning (Ellis, 2017).

Lyster and Ranta (1997) introduced a taxonomy of six types of feedback: recasts, elicitations, explicit correction, clarification requests, metalinguistic cues, and repetition. These have continued to be influential and widely adopted in CF research (Brown, 2016). In Table 2, we can see how Ellis (2017) summarized these and a few more types of feedback according to two of the distinctions discussed above.

Table 2. Types of Oral Corrective Feedback

\begin{tabular}{lll}
\hline & Implicit & Explicit \\
\hline Input-providing & Conversational recasts & $\begin{array}{l}\text { Didactic recasts } \\
\text { Explicit corrections }\end{array}$ \\
\hline \multirow{3}{*}{ Output-prompting } & Repetitions & Metalinguistic comments \\
& Clarification requests & $\begin{array}{l}\text { Elicitations } \\
\text { Paralinguistic signals }\end{array}$ \\
\hline
\end{tabular}

Numerous meta-analyses have been conducted in the area of oral CF. Most recent meta-analyses highlighted below have focused on the effectiveness of $\mathrm{CF}$, except for Brown (2016), which looked at the type and linguistic foci instead.

Li's (2010) meta-analysis considered 33 primary studies, and his findings are summarized here. For short-term effects, explicit feedback was more effective than implicit feedback. However, over a longer-term, implicit feedback effects were either sustained or even improved. Shorter-term treatments were more effective than longer-term ones. Studies in foreign language contexts had more substantial effects than in second language ones. Li (2010) also called for 
pre-tests to be administered or reported, and for more consistent categorization of feedback types. In addition, $\mathrm{Li}$ (2010) brought up the need for more research on moderating variables such as proficiency, target structure complexity, and interlocutor type.

Miller and Pan (2012) conducted a meta-analysis of recasts, in particular, involving a total number of 40 empirical studies. They found that recasts may not have such a significant impact, as uptake following recasts might not necessarily lead to acquisition. Another issue is the salience of recasts, as they might be relatively implicit and not lead to noticing by the learner. The question then is whether the impact is long-lasting or only immediate (Miller \& Pan, 2012); while the short-term impact is welcome, researchers and practitioners are ultimately interested in the longer-term impacts of instructional intervention. They also highlighted the need for reporting or control of the age group of the participants. They found that most studies looked at university-level or mixedage groups, which might explain the rather substantial variations in effect sizes (Miller \& Pan, 2012).

Lyster et al. (2013) is a state-of-the-art article on oral CF. They considered teacher and learner preferences, in addition to contentious issues such as learner uptake, where it is unclear if uptake contributes to acquisition in essential ways. Their claim about uptake echoes Miller and Pan's (2012) findings, stating that uptake after recasts does not guarantee acquisition. They looked at both laboratory and classroom research and found that $\mathrm{CF}$ was overall more effective than no CF. One issue discussed was the relative effectiveness of recasts and prompts. They acknowledged each type of CF's complex nature and how a variety of interventions might be more useful than trying to identify the single best kind. Specifically, they mentioned paralinguistic signals (of which gesture is one) as being under-researched and called for research on how CF can help in phonological development, especially suprasegmentals (Lyster et al., 2013).

In a departure from the focus on effectiveness, Brown (2016) chose to focus on observational studies and to consider the kind of $\mathrm{CF}$ and target structures. Besides finding that teachers used recasts (57\%) more than prompts $(30 \%)$, he also noted that grammatical errors received the majority of the feedback (43\%). $\mathrm{He}$ then identified several factors affecting $\mathrm{CF}$, including learner proficiency, teacher experience, and the teaching context. Finally, Brown (2016) called for better coding of feedback types, better reporting of teacher background data, and details regarding the classroom context and inter-rater reliability measures. The 
inclusion of more comprehensive information would ensure more accurate and reliable interpretations of research findings within $\mathrm{CF}$.

\section{GESTURE IN CORRECTIVE FEEDBACK}

There has been a considerable amount of research done on $\mathrm{CF}$, as discussed in the previous section. However, there are far fewer studies regarding the use of gesture during feedback, otherwise known as nonverbal CF (Wang \& Loewen, 2016). Though this research area is still in its infancy, there have been both observational and interventional studies conducted to explore nonverbal CF (Nakatsukasa \& Loewen, 2017). Nevertheless, there remains a dearth of studies focused only in the area of pronunciation. Therefore, relevant studies on nonverbal CF across various areas (such as grammar or vocabulary) will be considered too, as they can provide valuable insights regarding the role of gesture in pronunciation. These studies can provide researchers with useful insights and directions when investigating the efficacy of gesture-based corrective feedback in pronunciation in varied classroom contexts.

One of the first studies was conducted by Davies (2006), which explored uptake that followed paralinguistic CF. Nakatsukasa and Loewen (2017) noted that while Davies (2006) found that feedback with accompanying paralinguistic features resulted in higher uptake, he did not strictly define the features used in the study. Davies (2006) identified two kinds of recasts, either with paralinguistic FonF that focuses on form and is hypothesized to result in uptake or non-paralinguistic FonF that focuses on meaning and aims for topic continuation.

More recently, Wang and Loewen (2016) conducted an observational review of nonverbal behavior in nine university-level classrooms. They examined nonverbal $\mathrm{CF}$ in the following contexts: integrated speaking and listening, integrated reading and writing, academic reading, and grammar. Wang and Loewen (2016) found that $60.2 \%$ out of 507 CF episodes contained nonverbal behavior, which clearly shows that considering teachers 'behavior without a nonverbal element would not give a complete picture. They reported that the most frequent behaviors were nodding or shaking one's head and pointing (Wang \& Loewen, 2016). However, gestures in McNeill's four categories (i.e., iconic, metaphoric, deictic, and beat) were present as well. Although limited in scope, this study demonstrates the significance of teachers' 
nonverbal behavior in the classroom and justifies the need for further research in this area.

Aside from observational studies, a couple of interventional studies have also been reported in the literature. Nakatsukasa (2016) investigated the effect of gestures with recasts on the acquisition of English locative prepositions. Forty-eight low-intermediate students were split into three groups: no feedback, recasts-only (R), and recasts with gestures (RG). Gestures were described as "geometric" in nature, according to the preposition's meaning (Nakatsukasa, 2016, p. 779). Referring to McNeill's (1992) categorization, this would seem to indicate an iconic kind of gesture. Learners performed two information-gap communicative tasks using the target structures, while instructors provided feedback according to the three conditions. The treatment session was videotaped, and the post-test was conducted one week later. A select group also participated in a stimulated recall session. Overall, both the R and RG groups performed better than the control group in the immediate post-test; however, on the delayed post-test, the RG group outperformed the other groups. This study provides positive confirmation of the long-term effectiveness of recasts with gestures, at least in locative prepositions.

In a later study, Nakatsukasa (2019) explored the effect of gestures during recasts on the acquisition of the regular past tense in English. Fifty-nine lowintermediate students were divided into three groups, with conditions similar to the study above: no feedback, R, and RG. "Point-back" gestures were used to indicate the past (Nakatsukasa, 2019, p. 12). This would seem to be metaphoric in nature, in reference to McNeill's categories. A pre-test, post-test (1-3 days after treatment), and delayed post-test (7-9 days after treatment) were assigned. Communicative tasks (picture-ordering and information-gap) were carried out, during which instructors gave feedback according to the three conditions. Eventually, in a departure from the previous study, all three groups exhibited similar results, which would indicate a limited effect of gesture during feedback in this case (Nakatsukasa, 2019). This study indicates the need for further research to be conducted in various target linguistic structures and in a broader L2 teaching context, as it may not be the case that gesture with recasts would always be effective. Productive areas of research will be explored in the latter part of this article. 


\section{GESTURES IN THE TEACHING OF PRONUNCIATION}

A small number of studies have looked at nonverbal gestures during the instruction of pronunciation features. While they are not specifically to do with feedback, it would be interesting to look at their methodology and results. The approaches taken with regard to the methodology are especially interesting for potential research in the area of $\mathrm{CF}$ in pronunciation teaching, as they illuminate how gesture can be used to help learners acquire such features. Understanding the mechanics of such use will be helpful in operationalizing gesture as an independent variable in future research. First, a brief consideration of a few studies on learners of Japanese will be presented before focusing on more relevant ones conducted on learners of English.

In a chapter on nonverbal feedback, Nakatsukasa and Loewen (2017) reviewed a series of studies that examined the effect of gesture on L1 English learners 'acquisition of complicated phonetic features in Japanese. These included such targets as long and short vowels (Hirata et al., 2014) and single versus double consonants (Kelly \& Lee, 2012). Overall, gestures were found to be of little significance. However, the participants were not actual L2 learners of Japanese. Nakatsukasa and Loewen (2017) thus caution that the findings may not represent actual learners trying to acquire an additional language.

Gluhareva and Prieto (2017) explored the potential effect of beat gestures during instruction on learners' accentedness in spontaneous discourse. The participants were twenty undergraduates who were bilingual in Catalan and Spanish with an upper-intermediate level of English, studying Applied Languages or Translation and Interpreting. Training videos portraying easy and difficult prompts with two conditions (beat or no beat) were shown, with the beats corresponding to stressed syllables and words that were semantically important; care was taken to ensure the beat gestures co-occurred naturally with speech, and thus, there was a portion of stressed syllables that did not co-occur with a beat (Gluhareva \& Prieto, 2017). Pre-tests and post-tests were conducted where participants reacted to a prompt and were rated on a Likert scale by five native English speakers who were not trained in linguistics or teaching. Findings indicated that beat gestures were helpful in training for higher-difficulty items, which called for lengthier responses arising through discourse, such as describing the state of an apartment (Gluhareva \& Prieto, 2017). Overall, the small sample size and niche background of the participants limits the generalizability of this study. 
Llanes-Coromina et al. (2018) studied the effect of beat gestures during training on learners 'performance in a reading aloud task. Fifty-nine Catalanspeaking high schoolers at an elementary or lower-intermediate level of English were divided into two treatment conditions: beat gesture and non-beat gesture. The difference between the previous study and this one is that students were asked to produce the beat gestures themselves. Similar to the previous study, the participants' recordings were assessed through a Likert scale questionnaire by five native speakers of American English, as instructors identified this as the variety of English they were most familiar with. Findings indicated producing gestures helped the treatment group improve in terms of accentedness, comprehensibility, and fluency, as they received higher scores indicating "native-like" performance from the five judges on these measures. This is especially significant considering the effects held although the post-test text was more complex than the training ones (Llanes-Coromina et al., 2018).

Recently, lizuka et al. (2020) examined whether handclapping had an effect on the acquisition of L2 Japanese segmentals, specifically long vowels, moraic nasals, and geminates. The participants were thirty-one undergraduate students at a university in America, enrolled in a beginner-level Japanese class that focused on communicative skills. There were two groups, one that received instruction without gesture, and one that received instruction with handclapping performed by the instructor. In response, the first group repeated after the instructor three times, while the second group repeated three times accompanied by handclapping. Thus, the second group both perceived and performed the accompanying gesture of handclapping. Both receptive and productive knowledge was tested in the form of a pretest, an immediate posttest, and a delayed posttest. Receptive knowledge was tested in a dictation task, while productive knowledge was assessed through a picture elicitation task. The receptive task scored participants on a binary scale, depending on their successful identification of the target linguistic feature, disregarding any other errors in orthography or other parts of the word; unsuccessful identification resulted in a score of zero while successful identification received one point. The productive task was subjectively assessed by two native speakers, and objectively assessed using a speech analysis software. Overall, findings indicated a positive impact of handclapping on receptive knowledge, but a negligible impact on productive knowledge. This study is significant as it highlights the beneficial effect of gesture is "not limited to segmental" and can indeed be "extended to segmentals" (Iizuka et al., 2020, p. 27). 
Finally, besides the empirical studies discussed above, Smotrova (2017) conducted an observational study where she collected video recordings of pronunciation instruction in an ESL class for beginners at a university. These lessons included suprasegmental features such as word stress and syllabification. After a microanalysis of these lessons was conducted, findings indicated that the teacher used gestures as an instructional tool, which were then picked up and imitated by students in their learning process, thus facilitating the acquisition of the target features, such as syllables, word stress, and rhythm (Smotrova, 2017). Significantly, the teacher often used pre-planned "intentional instructional gestures" (IIG) during instruction and feedback, encouraging students to imitate these and use them creatively as well (Smotrova, 2017, p. 68). Besides the purely instructional value of gesture, the potential of gesture to create humor and a positive learning environment was mentioned as well (Smotrova, 2017).

\section{PEDAGOGICAL IMPLICATIONS}

Recalling how McNeill (2005) conceived of speech and gesture as a holistic system, it is only natural that various gestures arise organically during a speech. However, teachers could use specific gestures more purposefully during instruction. These meaningful gestures could serve to accentuate meaning in vocabulary instruction or draw attention to specific pronunciation features (Smotrova, 2017). Such gestures can be defined as catchments, which are recurrent gestures occurring during discourse that give clues to the "cohesive linkages" in the text they accompany (McNeill, 2005, p. 116). These catchments are pedagogically significant as they reflect understanding on the students 'part and acknowledgment on the teachers 'part (Smotrova, 2017). More specifically, catchments ensure coherence in classroom interaction across speakers and modalities, as well as create "surprise and contingency" (Smotrova \& Lantolf, 2013, p. 413). Recalling Schmidt's noticing hypothesis, this element of surprise would lead to greater awareness, thus facilitating uptake and acquisition.

While there is no doubt that teachers are currently using gestures in class, whether consciously or not, a framework has been proposed to guide the use of gesture in teaching areas such as pronunciation or pragmatics (Acton et al., 2013; Burri et al., 2019). The essential, haptic-integrated English pronunciation (EHIEP) framework utilizes movement and touch to teach, resulting in pedagogical movement patterns (PMP) to be used at any point in the class, whether in a presentation or during corrective feedback (Acton et al., 2013). 
Specific PMPs were designed to cover areas of pronunciation such as vowels, stress, and intonation. In one instance, PMPs to distinguish between tense and lax vowels (e.g., specific movements accompanying vowels such as /i:/ versus $/ \mathrm{I} /$ ) were taught to postsecondary students and used by their teacher during corrective feedback; overall, the class reported greater awareness of the target features (Acton et al., 2013). Given the potential of gesture to facilitate and accelerate language acquisition, it is worth exploring how exactly teachers may use intentional gestures effectively in their teaching.

A few concrete examples of classroom activities incorporating gesture during pronunciation instruction will be discussed here. These will provide a clearer idea of how gesture is currently used by teachers, as well as a guide regarding the choice of independent variables in designing research to investigate the effect of gesture on pronunciation errors in SLA. Gestures accompanying both segmental and suprasegmental information will be discussed.

Segmental information has to do with vowels and consonants, while suprasegmental information concerns features such as rhythm, linking, and syllable or sentence stress (Chan, 2018). Regarding segmental information, one activity involves the teacher performing two distinct gestures while producing continuant and noncontinuant sounds. More specifically, the teacher holds her hand before her torso with palm facing inward and moves it in "forward, circular, fluid" motions for continuant sounds such as nasals, fricatives, and vowels; meanwhile, the teacher keeps her hand in a stationary position in front of her torso for noncontinuant sounds such as plosives (Chan, 2018, p. 56). Another activity with segmental information involves distinguishing vowel pairs, requiring students to produce a gesture to demonstrate their knowledge productively. The teacher asks students to identify the target vowel or consonant sound in a minimal pair by holding up one or two fingers (e.g. to hold up one finger to identify /b/ when she says 'bat' and two fingers to identify /h/ in 'hat') (Chan, 2018, p. 57).

On the other hand, there are activities that focus on suprasegmental knowledge too. For instance, Acton et al. (2013) describe a technique named "Rhythmic Feet Fight Club", where students perform "boxing-like movements" to focus on rhythm and focal stress (p. 240). Another activity practises the four basic patterns of intonation (level, fall, rise, and rise-fall) by moving the hand in corresponding upward and downward movements, or in a straight line for the level pattern (Burri et al., 2019). 
Those are examples of the earlier-discussed PMPs (Acton et al., 2013) or meaningful movements (Smotrova, 2017) that are used by both teachers and students in the classroom. It is worth further investigation as there is a mismatch between research and practice in this case, as teachers continue to use gesture (whether in a structured way or not) in class as they believe in its efficacy, while there remains a lack of research that supports this belief (Iizuka et al., 2020). Examining these specific gestures accompanying either segmental or suprasegmental information would deepen our understanding of whether such non-verbal feedback helps, hinders, or has no measurable effect on the acquisition of pronunciation features in SLA. A greater body of research would provide a valuable guide for teachers to systematically teach pronunciation features and create effective practice activities for students.

\section{FURTHER RESEARCH}

The discussion in the earlier sections of this article has brought up several promising and productive research areas on the use of gesture in language teaching. For example, as the at-times inherent nature of recasts may not lead to noticing or uptake (Miller \& Pan, 2012), it would be worthwhile to see if gestures would make recasts more salient. This could be investigated through more robust research design, as outlined in the following paragraphs.

Our review of the literature has also brought up several concerns that need to be addressed in future research. Firstly, pre-tests and consistent typology were not always present, which may have affected the validity of the results (Brown, 2016; Li, 2010). Secondly, there is the notion that uptake does not equal acquisition (Lyster et al., 2013; Miller \& Pan, 2012). Rather than assuming instances of uptake as evidence of acquisition, an experimental design incorporating a post-test and a delayed post-test to assess performance and retention would be more effective in discerning whether students have truly acquired the target structure(s). Next, given the wide range of gestures possible, consistent coding of feedback types is important (Brown, 2016). Finally, studies with speaker judgments often included only 'native 'speakers (Gluhareva \& Prieto, 2017; Llanes-Coromina et al., 2018), necessitating unspecific judgment criteria such as accentedness, which may be wholly subjective. Instead, trained ESL teachers could be enlisted due to the degree of linguistic knowledge necessary to judge the acquisition of suprasegmentals such as word stress. This would result in more robust findings. Finally, the classification of gestures into 
various types has been well-established (e.g. McNeill, 1992). However, lizuka et al., 2020) posit that a finer distinction may be made in terms of the nature of the gesture: visual, kinesthetic, auditory, or a mixture of these; for instance, they suggest laboratory conditions where participants may perceive the gesture of handclapping with the sound muted. This would allow a comparison with another group of participants who perceive the gesture along with the auditory component, in order to pinpoint the precise reason for any effect found. In future interventional studies, if a positive effect is indeed found, it would also be interesting to compare the effect sizes of treatment groups where learners are receptively exposed to gestures against groups where learners themselves produce the gestures during uptake. In other words, it would be interesting to consider the use of gesture in two cases: one where students only see a gesture and one where students both see and perform a gesture. Although it has been found that learner-produced gestures have a more significant effect on comprehension than observing teacher-produced ones, it is still unknown what kinds of gestures are the most effective (Dargue et al., 2019). Next, considering the participants' background, it would be good to explore the impact in groups with different ages and levels. So far, most studies seem to have focused on adult learners or learners in a university setting (e.g., Gluhareva \& Prieto, 2017; Smotrova, 2017; Wang \& Loewen, 2016). Effect sizes may vary for the same treatment at higher and lower levels.

As research to date has not adequately factored in individual differences, future research should perhaps include such factors as motivation and language learning strategies, which have been shown to affect language acquisition (Loewen, 2015). For instance, $\mathrm{Li}$ (2013) found that recasts had a more significant effect on learners with higher analytic ability, provided that the target structure was within their processing capacity. It would be interesting to explore if utilizing beat gestures during recasts would enhance this efficacy, or indeed if they could help learners with lower language analytic ability to be more receptive to recasts. Another fruitful area of research might be to examine the effect of gesture on intercultural communication, given the multicultural contexts of L2 classrooms these days. Ulrich-Verslycken (2019) noted the potential for miscommunication or offense, given the existence of polysemous gestures that look the same but mean very different things in different cultures. It would thus be interesting to compare the effect of gesture on different student populations, and what might be done to mitigate confusion and enhance efficacy in the classroom. 
356 TEFLIN Journal, Volume 31, Number 2, July 2020

\section{CONCLUSIONS}

To conclude, the use of gestures in corrective feedback is ripe for further research, especially in the area of pronunciation instruction, perhaps with a focus on suprasegmentals (Lyster et al., 2013). However, recent research indicates the potential for the positive impact of gesture on receptive knowledge of segmentals as well (Iizuka et. al, 2020). Gesture naturally co-occurs with speech and is currently in use by both teachers and students as part of the learning process. It is hoped that further research, whether observational or interventional in nature, will shed light on how it is used to determine the best practices moving forward. Such results could be incorporated into teacher training to facilitate confident and effective instruction, and into student training to allow for better selfdirected learning strategies.

\section{REFERENCES}

Acton, W., Baker, A., Burri, M., \& Teaman, B. (2013). Preliminaries to hapticintegrated pronunciation instruction. In J. Levis \& K. LeVelle (Eds.), Proceedings of the 4th Pronunciation in Second Language Learning and Teaching Conference (pp. 234-244). Iowa State University.

Brown, D. (2016). The type and linguistic foci of oral CF in the L2 classroom: A meta-analysis. Language Teaching Research, 20(4), 436-458. https://doi.org/10.1177/1362168814563200

Burri, M. S., Baker, A. A., \& Acton, W. (2019). Proposing a haptic approach to facilitating L2 learners' pragmatic competence. Humanising Language Teaching, 21(3), 28. http://hltmag.ng3.devwebsite.co.uk/june19/proposinga-haptic-approach

Chan, M. J. (2018). Embodied pronunciation learning: Research and practice. CATESOL Journal, 30(1), 47-68.

Dargue, N., Sweller, N., \& Jones, M. P. (2019). When our hands help us understand: A meta-analysis into the effects of gesture on comprehension. $\begin{array}{llll}\text { Psychological Bulletin, } & \text { 145(8), }\end{array}$ https://doi.org/10.1037/bul0000202

Davies, M. (2006). Paralinguistic focus on form. TESOL Quarterly, 40(4), 841855. https://www.jstor.org/stable/40264316.

Ellis, R. (2017). Oral CF in L2 classrooms: What we know so far. In H. Nassaji, \& E. Kartchava (Eds.), Corrective feedback in second language teaching 
and learning: Research, theory, applications, implications (pp. 3-18). Routledge.

Gluhareva, D., \& Prieto, P. (2017). Training with rhythmic beat gestures benefits L2 pronunciation in discourse-demanding situations. Language Teaching Research, 21(5), 609-631. https://doi.org/10.1177/1362168816651463

Hirata, Y., Kelly, S. D., Huang, J., \& Manansala, M. (2014). Effects of hand gestures on auditory learning of second-language vowel length contrasts. Journal of Speech, Language, and Hearing Research, 57(6), 2090-2101. https://doi.org/10.1044/2014_JSLHR-S-14-0049

Iizuka, T., Nakatsukasa, K., \& Braver, A. (2020). The efficacy of gesture on second language pronunciation: An exploratory study of handclapping as a classroom instructional tool. Language Learning. Advanced online publication. https://doi.org/10.1111/lang.12415

Kelly, S. D., \& Lee, A. L. (2012). When actions speak too much louder than words: Hand gestures disrupt word learning when phonetic demands are high. Language and Cognitive Processes, 27(6), 793-807. https://doi.org/10.1080/01690965.2011.581125

Li, S. (2010). The effectiveness of CF in SLA: A meta-analysis. Language Learning, 60(2), 309-365. https://doi.org/10.1111/j.14679922.2010.00561.x

Li, S. (2013). The interactions between the effects of implicit and explicit feedback and individual differences in language analytic ability and working memory. The Modern Language Journal, 97(3), 634-654. https://doi.org/10.1111/j.1540-4781.2013.12030.x

Llanes-Coromina, J., Prieto, P., \& Rohrer, P. L. (2018). Brief training with rhythmic beat gestures helps L2 pronunciation in a reading aloud task. In K. Klessa K, J. Bachan, A. Wagner, M. Karpiński, \& D. Śledziński (Eds.), Proceedings of the 9th International Conference on Speech Prosody; 2018 June 13-16; Poznań, Poland. [Lous Tourils] (pp. 498-502). International Speech Communication Association (ISCA).

Loewen, S. (2015). Introduction to instructed second language acquisition. Routledge.

Loewen, S., \& Sato, M. (2018). Interaction and instructed second language acquisition. Language Teaching, 51(3), 285-329. https://doi.org/10.1017/S0261444818000125 
Lyster, R., \& Ranta, L. (1997). CF and learner uptake: Negotiation of form in communicative classrooms. Studies in Second Language Acquisition, 19(1), 37-66. https://doi.org/10.1017/S0272263197001034

Lyster, R., Saito, K., \& Sato, M. (2013). Oral corrective feedback in second language classrooms. Language Teaching, 46(1), 1-40. https://doi.org/10.1017/S0261444812000365

McCafferty, S., \& Gullberg, M. (2008). Gesture and SLA: Towards an integrated approach [Special issue]. Studies in Second Language Acquisition, 30(2), 131-251. https://doi.org/10.1017/S0272263108080285

McNeill, D. (1992). Hand and mind: What gestures reveal about thought. University of Chicago Press.

McNeill, D. (2005). Gesture and thought. University of Chicago Press.

Miller, P. C., \& Pan, W. (2012). Recasts in the L2 classroom: A meta-analytic review. International Journal of Educational Research, 56, 48-59. https://doi.org/10.1016/j.ijer.2012.07.002

Nakatsukasa, K. (2016). Efficacy of recasts and gestures on the acquisition of locative prepositions. Studies in Second Language Acquisition, 38(4), 771799. https://doi.org/10.1017/S0272263115000467

Nakatsukasa, K. (2019). Gesture-enhanced recasts have limited effects: A case of the regular past tense. Language Teaching Research, 1-26. https://doi.org/10.1177\%2F1362168819870283

Nakatsukasa, K., \& Loewen, S. (2017). Nonverbal feedback. In H. Nassaji, \& E. Kartchava (Eds.), Corrective feedback in second language teaching and learning: Research, theory, applications, implications (pp. 158-173). Routledge.

Schmidt, R. (2012). Attention, awareness, and individual differences in language learning. In A. U. Chamot, S. Bhatt, W. M. Chan, \& I. Walker. (Eds.), Perspectives on individual characteristics and foreign language education (pp. 27-50). De Gruyter Mouton.

Smotrova, T. (2017). Making pronunciation visible: Gesture in teaching pronunciation. TESOL Quarterly, 51(1), 59-89. https://doi.org/10.1002/tesq.276

Smotrova, T., \& Lantolf, J. P. (2013). The function of gesture in lexically focused L2 instructional conversations. The Modern Language Journal, 97(2), 397-416. https://www.jstor.org/stable/43651646 
Thompson \& Renandya, Use of Gesture for Correcting Pronunciation Errors 359

Ulrich-Verslycken, K. (2019). Nonverbal signaling in the EFL classroom: Implications for English teaching in South Korea. Humanising Language Teaching, 21(6). https://www.hltmag.co.uk/dec2019/nonverbal-signaling

Wang, W., \& Loewen, S. (2016). Nonverbal behavior and corrective feedback in nine ESL university-level classrooms. Language Teaching Research, 20(4), 459-478. https://doi.org/10.1177/1362168815577239

Wong, C. S. (2016). Teaching pronunciation to learners of English as a lingua franca. In W. A. Renandya, W.A. \& H. P. Widodo (Eds.), English language teaching today (pp. 241-255). Springer. 